\title{
PENGEMBANGAN INSTRUMEN TES MODEL IDEATION-EXPLANATION UNTUK MENGUKUR KEMAMPUAN BERFIKIR KREATIF DALAM PEMECAHAN MASALAH
}

\section{TEST INSTRUMENTS DEVELOPMENT OF IDEATION-EXPLANATION MODEL TO MEASURE CREATIVE THINKING ABILITY IN PROBLEM SOLVING}

\author{
Ahmad Busyairi1* dan Parlindungan Sinaga ${ }^{2}$ \\ 1Program Studi Pendidikan Fisika FKIP, Universitas Mataram, Mataram, Indonesia; \\ ${ }^{2}$ Program Studi Pendidikan Fisika FPMIPA, Universitas Pendidikan Indonesia, Bandung, Indonesia . \\ *Email: ahmad.busyairi@unram.ac.id
}

Diterima: 14 Februari 2020. Disetujui: 27 Februari 2020. Dipublika sikan: 9 Januari 2021

\begin{abstract}
Abstrak: Kemampuan berpikir kreatif khusunya kreatif dalam konteks pemecahan masalah sangat dibutuhkan di era revolusi industri 4.0 ini. Oleh karena itu, setiap individu hendaknya tidak hanya dibekali dengan kemampuan pemecahan masalah semata melainkan juga harus dilatihkan kemampuan berpikir kreatif agar nantinya mereka dapat menyelesaiakan permasalahan dengan cara-cara yang kreatif. Penelitian ini bertujuan untuk mengembangkan instrumen tes untuk mengukur kemampuan berpikir kreatif dalam konteks pemecahan masalah. Jenis penelitian ini adalah penelitian pengembangan (Research and Development) dengan model 4D. Pengembangan model 4D terdiri dari empat tahapan yaitu; pendefinisian, perancangan, pengembangan, dan penyebarluasan. Instrumen tes yang dikembangkan dalam penelitian ini berbentuk Ideation-Explanation (I-E model). Adapun jumlah item soal (permasalahan terbuka) terdiri atas 5 (lima) permasalahan yang masing-masing permasalahan diikuti oleh 2 (dua) buah pertanyaan. Hasil analisis data memperlihatkan bahwa semua item soal valid dengan reliabilitas 0.79 dalam kategori tinggi. Ini menunjukkan bahwa instrumen tes yang sudah dikembangkan layak untuk digunakan.
\end{abstract}

Kata Kunci: Kemampuan Berpikir Kreatif, pemecahan masalah, modelIdeation-Explanation, Arus Listrik

\begin{abstract}
Creative thinking ability especially creative in problem solving is very needed in the era of industrial revolution 4.0. Therefore, every individual should not only be equipped with problem solving ability but must also be trained their creative thinking ability so that they can solve problems in creative ways. This research aims to develop test instrumens to measure the creative thinking ability in problem solving process. This research is a development research by using the 4D model. 4D model development consisted of four stage; define, design, develop, and disseminate. The test instrument developed in this research took the form of an Ideation-Explanation (I-E model). The number of test items (open-ended problems) consists of 5 (five) problems, each problem followed by 2 (two) questions. Based on the results of data analysis shows that all items are valid with the reliability of 0.79 in the high category. This shows that the developed test instrument is feasible to use.
\end{abstract}

Keywords: Creative Thinking Ability, Problem Solving, Ideation-Explanation Model, Electric Current

\section{PENDAHULUAN}

Kemampuan berpikir kreatif khususnya kreatif dalam konteks pemecahan masalah sangat dibutuhkan di zaman globalisasi yang serba komplek dan dinamis ini. Kemampuan ini dibutuhkan karena pada setiap profesi tentunya memiliki permasalahannya sendiri yang harus dipecahkan. Tanpa keteramplan berpikir kreatif, seseorang cenderung akan menggunakan solusi yang sudah usang untuk memecahkan permasalahan yang dihadapi meskipun terkadang solusi yang ditawarkan sudah tidak sesuai dengan situasi dan kondisi [1]. Untuk itu, setiap individu hendaknya tidak hanya dibekali dengan kemampuan pemecahan masalah semata melainkan juga harus dilatihkan kemampuan berpikir kreatif agar nantinya mereka dapat menyelesaiakan permasalahan dengan cara-cara yang kreatif [2].

Kemampuan berpikir kreatif adalah kemampuan untuk memikirkan banyak kemungkinan,menggunakan cara yang bervariasi (baik secara konseptual ataupun artistik), menggunakan sudut pandang yang berbeda, dan memikirkan sesuatu yang baru dan tidak biasa namun berfungsi untuk membuat poin yang menarik [3]. Mednick mengatakan bahwa berpikir kreatif merupakan sebuah proses mengasosiasi ide-ide yang sudah ada menjadi kombinasi-kombinasi yang tidak biasa hingga ahirnya terbentuk ide-ide baru yang asli [4]. Torrance mencoba menghubungkan kreativitas dengan proses pemecahan masalah dengan mendefinisikan kemampuan berpikir kreatif sebagai sebuah proses menjadi sensitif terhadap masalah, kekurangan, kesenjangan dalam pengetahuan, ketidak sesuaian, dan merasa tertarik untuk mencarikan solusi [5]. Den gan kata lain, ciri-ciri dari orang yang kreatif adalah ia melihat masalah di mana yang lainnya tidak. Seseorang yang tidak peka terhadap masalah menandakan orang tersebut tidak kreatif. 
Upaya untuk meningkatkan kemampuan berfikir kreatif telah menjadi salah satu prioritas dalam dunia pendidikan. Hal ini tercermin dari tujuan pendidikan sesuai dengan yang tertuang dalam kurikulum 2013 yaitu untuk menghasilkan insan indonesia yang produktif, kreatif, inovatif, afektif melalui penguatan sikap, keterampilan, dan pengetahuan yang terintegrasi [6]. Guru sebagai ujung tombak dalam dunia pendidikan semestinya mematuhi dan menjalankan amanah tersebut. Dalam kegiatan pembelajaran, guru sebaiknya tidak hanya menanamkan konsep-konsep ilmiah kepada siswa terkait materi yang diajarkan melainkan juga harus melatihkan kemampuan berfikir kreatif mereka.

Penilaian merupakan proses yang penting di dalam pembelajaran. Penilaian dapat memberikan timbal balik pada guru dan siswa. Penilaian juga mampu memberikan motivasi pada siswa agar lebih baik lagi. Bahkan penilaian bisa mempengaruhi perilaku belajar karena siswa cenderung mengarahkan gaya belajarnya sesuai dengan keriteria penilaian guru. Oleh karena itu selain sebagai bahan evaluasi, instrumen penilaian juga memiliki peranan yang penting dalam tercapainya tujuan pembelajaran sesuai dengan yang diharapkan.

Kenyataan di lapangan nampaknya masih belum sesuai dengan tujuan pembelajaran seperti yang dipaparkan di atas. Berdasarkan hasil studi pendahuluan pada salah satu sekolah yang ada di kabupaten Bandung memperlihatkan bahwa, guru jarang sekali mengajak siswa untuk memecahkan permasalahan yang bersifat terbuka (open-ended problem) sebagai upaya untuk melatihkan kemampuan berpikir kreatif siswa. Begitu juga pada tahap penilaian, soal-soal yang biasanya diberikan kepada siswa adalah soal-soal kognitif yang bersifat tertutup (close problem) yang penyelesaiannya langsung pada pemakaian persamaan matematis yang sudah ada. Setelah dilakukan studi lebih lanjut, diperoleh informasi bahwa salah satu yang menjadi alasan kenapa guru jarang melatihkan kemampuan berfikir kreatif siswa adalah guru mengalami kesulitan dalam membuat soal dan rubrik penilaian untuk mengukur kemampuan berfikir tersebut. Oleh karena itu, peneliti berencana untuk membuat instrumen tes untuk mengukur kemampuan berfikir kreatif siswa khususnya pada materiarus listrik.

Sejauh ini, instrumen tes kemampuan berfikir kreatif standar yang sudah dikembangkan oleh beberapa ahli yaitu: test of divergent thinking, creativity test for children, torrance test of creative thinking, dan creativity assessment packet [7]. Instrumen-instrumen tes tersebut biasanya digunakan sebagai acuan dalam pengembangan instrumen tes kemampuan berfikir kreatif. Berdasarkan studi pustaka memperlihatkan bahwa pengembangan instrumen tes kemampuan berfikir kreatif di Indonesia sebagian besar besar mengadaptasi bentuk Torrance Tests of Creative Thinking (TTCT). TTCT yang dikembangkan oleh Torrance terdiri dari dua versi yaitu TTCT verbal dan TTCT vigural. Aktivitas yang dinilai pada TTCT verbal terdiri dari lima aktivitas yaitu; bertanya, menebak, mengembangkan produk, memanfaatkan produk dengan cara yang tidak biasa, dan bertanya dengan pertanyaan yang tidak biasa. Sedangkan aktivitas yang dinilai pada TTCT vigural terdiri dari tiga aktivitas yaitu; membuat gambar, melengkapi gambar, melanjutkan ga mbar dengan garis [8].

Pengembangan instrumen tes yang terkait dengan ilmu IPA (dalam penelitian ini ilmu Fisika) harus mempertimbangkan konsep-konsep yang terkandung dalam ilmu fisika itu sendiri. Dengan demikian, untuk mengukur kemampuan berfikir kreatif siswa khususnya kemampuan berfikir kreatif dalam proses pemecahan masalah dengan menggunakan konsepkonsep fisika nampaknya tidak cukup hanya menggunakan tes verbal dan vigural dari Torrance. Torrance juga menyatakan bahwa tes TTCT tidak dapat menilai semua dimensi kreativitas. Perolehan skor yang tinggi pada TTCT tidak menjamin seseorang disebut kreatif. Oleh karena itu, Kim menjelaskan bahwa perlu ada bentuk tes lain untuk melengkapi tes TTCT tersebut [8].

\section{METODE PENELITIAN}

Jenis penelitian ini merupakan penelitian pengembangan (Research and Development) dengan model 4D. Tahap pengembangan pada penelitian model 4D terdiri dari 4 tahap yaitu pendefinisian (define), perancangan (design), pengembangan (develop), dan penyebaran (disseminate) [9]

Data hasil penelitian ini berupa data kualitatif dan data kuantitatif. Data kualitatif diperoleh dari hasil validasi isi oleh beberapa ahli. Para ahli diminta memberikan tanggapan berupa keterangan apakah instrumen tes yang sudah dikembangkan tanpa perbaiakan, ada perbaikan atau mungkin dirombak total. Tenaga ahli yang dilibatkan da lam validasi isi ini berjumlah 3 orang. Validasi isi ini dilakukan dengan melihat kesesuaian antara isi instrument dengan indikator kemampuan berpikir kreatif dalam pemecahan masalah, kesesuaian antara soal dan jawaban, dan kesesuaian tata bahasa. Adapun data kuantitatif diperoleh dari hasil uji coba instrumen tes terhadap beberapa siswa SMA di kota Bandung. Uji coba dilakukan sebanyak 2 kali. Jumlah siswa yang terlibat dalam uji coba instrumen tes ini sebanyak 27 siswa.

Data hasil validasi isi oleh beberapa ahli kemudian dianalisis untuk mengetahui tingkat validitas isi instrumen tes. Valid itas isi berkaitan dengan tingkat keabsahan atau ketepatan suatu tes dalam mengukur apa yang seharusnya diukur. Begitu juga data hasil uji coba instrumen tes dianalisis untuk mengetahui tingkat reliabilitas instrumen tes. Reliabelitas adalah tingkat kesetabilan skor yang diperoleh ketika dilakukan ujian ulang dengan menggunakan tes yang sama pada situasi yang berbeda atau dari satu pengukuran ke pengukuran 
lainnya. Reliabilitas diukur dengan melihat korelasi antara hasil uji coba pertama dengan uji coba berikutnya. Tingkat reliabilitas soal pada penelitian ini diperoleh dari hasil uji korelasi product moment pearson [10].

$$
r_{\mathrm{xy}}=\frac{\mathrm{N} \sum \mathrm{XY}-\left(\sum \mathrm{X}\right)\left(\sum \mathrm{Y}\right)}{\sqrt{\left.\left\{\mathrm{N} \Gamma \cdot \mathrm{x}^{2}-r \Gamma \mathrm{v}\right)^{2}\right\}\left\{\mathrm{N} \Gamma \cdot \mathrm{v}^{2}-r \mathrm{v}^{2}\right\}}}
$$

Keterangan:

$$
\begin{aligned}
r_{x y} & =\text { koefisien korela si } \\
X & =\text { skor rata-rata tes pertama } \\
Y & =\text { skor rata-rata tes kedua } \\
N & =\text { jumlah subyek }
\end{aligned}
$$

\section{HASIL DAN PEMBAHASAN}

Seperti yang sudah dijelaskan sebelumnya bahwa penelitian ini terdiri dari 4 tahapan yaitu; pendefinisian (define), perancangan (design), pengembangan (develope), dan penyebaran (disseminate).

\section{Tahap Pendefinisian}

Pada tahap ini, peneliti mengkaji literatur khususnya teori dan konsep yang relevan dengan instrumen tes yang akan dikembangkan. Peneliti juga melakukan kajian terhadap hasil penelitian terkait yang sudah dilakukan sebelumnya.

Berdasarkan hasil studi pendahuluan dan studi literatur diperolah bahwa bentuk instrumen tes yang akan dikembangkan dalam penelitian ini mengadaptasi bentuk instrumen tes yang sudah dikembangkan oleh Wang yaitu dengan menggunakan model I-E (IdeationExplanation) [11]. Instrumen tes model I-E di desain untuk mengukur kemampuan berfikir kreatif siswa dalam proses pemecahan masalah. Siswa diinstruksikan untuk menghasilkan banyak ide dari fenomena atau permasalahan terbuka (open-ended problem) yang disajikan. Setiap ide yang berhasil mereka temukan diberi alasan dan penjelasan kenapa mereka memilih ide-ide tersebut. Hal ini memungkinkan siswa untuk berfikir divergen dan konvergen secara terintegrasi dan berimbang karena prinsif utama dari kreativitas yaitu adanya keseimbangan antara berpikir divergen dan konvergen.

Kemampuan berfikir kratif yang menjadi fokus kajian dalam penelitian ini adalah kemampuan berfikir kreatif dalam pemecahan masalah. Oleh karena itu, dalam penelitin ini kemampuan berfikir kreatif siswa akan dilihat dari 2 aspek yaitu; kemampuan dalam menemukan masalah (problem finding) dan kemampuan dalam menemukan solusi (solution finding). Masing-masing aspek nantinya akan dilihat tingkatan kemampuan berfikir kreatifnya apakah siswa kreatif dalam menemukan masalah dan atau kreatif dalam menemukan solusi.

Indikator kemampuan berfikir kreatif yang digunakan dalam penelitian ini di ambil dari tiga indikator kemampuan berfikir Guilford, Torrance, silver, dan Munandar yaitu; kefasihan (fluency), kelenturan (flexibility), dan keaslian (originality). Kefasihan (fluency) merupakan kemampuan untuk menghasilkan banyak ide, gagasan, jawaban, penyelesaian masalah dan pertanyaan, memberikan banyak cara atau saran untuk melakukan berbagai hal serta selalu memikirkan lebih dari satu jawaban. Kelenturan (flexibility) merupakan kemampuan untuk melihat pertanyaan atau topik dari berbagai perspektif atau sudut pandang yang berbeda-beda, serta mampu mengubah cara pendekatan atau cara pemikiran. Keaslian (originality) merupakan mampu melahirkan ungkapan yang baru dan unik, memikirkan cara yang tidak lazim untuk mengungkapkan diri serta mampu membuat kombinasi-kombinasi yang tidak lazim dari bagian unsur (AL-Khatib, 2012).

Instrumen tes ini diperuntukkan untuk siswa Sekolah Menengah Atas (SMA). Oleh karena itu, peneliti akan menyesuaikan tingkat kesulitan item soal yang akan dikembangkan sesuai dengan jenjang pendidikan dari peserta didik (siswa) dengan mengacu pada Kompetensi Dasar (KD). Adapun materi fisika yang menjadi kajian dalam pengembangan instrumen tes ini adalah materiarus listrik.

\section{Tahap Perancangan}

Pada tahap ini, instrumen tes kemudian didesain mengacu dari hasil pendefinisian yang sudah dilakukan sebelumnya. Berikut adalah bentuk desain instrumen tes yang akan dikembangkan dalam penelitian ini.

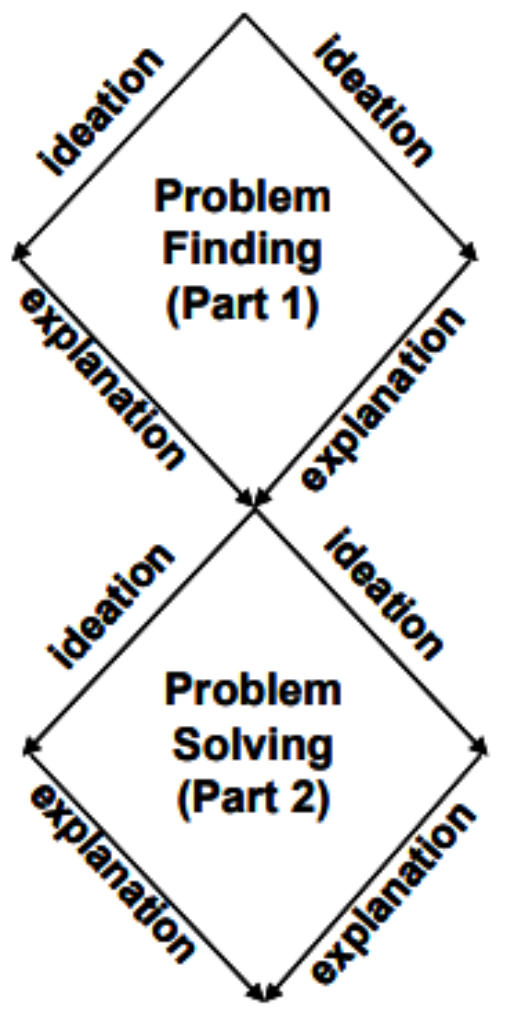

Gambar 1: Desain instrumen tes model IE 
Adapun bentuk lembar jawaban siswa dapat dilihat pada gambar berikut.

Please think about what difficulties you may encounter in the situation. Enumerate all ideas you have got in the following fields, and point out the reason of each idea

\begin{tabular}{c|c}
\hline Your Ideas & Reasons \\
\hline & \\
\hline & \\
\hline & \\
\hline & \\
\hline
\end{tabular}

\section{Tahap Pengembangan}

Tahap pengembangan merupakan tahap utama dari penelitian ini. Pada tahap ini, peneliti mulai membuat instrumen tes dengan mangacu pada desain yang sudah dibuat sebelumnya. Sebanyak 5 pokok soal berupa sebuah kejadian atau permasalahan terbuka (open-ended problem) disusun berdasarkan materi arus listrik. Tiap-tiap pokok soal diikuti 2 buah pertanyaan sehingga totalmenjadi 10 buah pertanyaan.

Gambar 2: lembarjawaban siswa model I-E

Tabel 3. Pedoman pensekoran kemampuan berfikir kreatif dalam pemecahan masalah

\begin{tabular}{|c|c|c|}
\hline Indikator & Keterangan & Skor \\
\hline \multicolumn{3}{|c|}{ Kemampuan Berfikir Kreatif dalam Menemukan Masalah (Problem Finding) } \\
\hline \multirow{5}{*}{$\begin{array}{c}\text { Kefasihan } \\
\text { (fluency) }\end{array}$} & Tidak mampu menemukan perma salahan yang relevan dari fenomena yang diberikan & 0 \\
\hline & Mampu menemukan satu perma salahan yang relevan dengan ala san yang sa lah & 1 \\
\hline & Mampu menemukan satu perma salahan yang relevan disertai a la san yang benar & 2 \\
\hline & Mampu menemukan beragam permasalahan yang relevan dengan alasan yang salah & 3 \\
\hline & Mampu menemukan beragam permasalahan yang benar disertaialasan yang benar & 4 \\
\hline \multirow{5}{*}{$\begin{array}{l}\text { Kelenturan } \\
\text { (flexibility) }\end{array}$} & Tidak mampu menemukan perma salahan yang relevan dari fenomena yang diberikan & 0 \\
\hline & Mampu menemukan satu perma salahan yang relevan namun dengan ala san yang salah & 1 \\
\hline & Mampu menemukan satu perma salahan yang relevan disertai a lasan yang benar & 2 \\
\hline & $\begin{array}{l}\text { Mampu menemukan beragam permasalahan dari berbagai perspektif atau sudut pandang } \\
\text { yang berbeda namun dengan alasan yang salah }\end{array}$ & 3 \\
\hline & $\begin{array}{l}\text { Mampu menemukan beragam permasalahan dari berbagai perspektif atau sudut pandang } \\
\text { yang berbeda disertai alasan yangbenar }\end{array}$ & 4 \\
\hline \multirow{5}{*}{$\begin{array}{l}\text { Keaslian } \\
\text { (originality) }\end{array}$} & Tidak mampu menemukan perma salahan darifenomena yang diberikan & 0 \\
\hline & Mampu menemukan satu perma salahan yang relevan dan unik dengan a lasan yang salah & 1 \\
\hline & Mampu menemukan satu perma salahan yang relevan dan unik dengan a la san yangbenar & 2 \\
\hline & $\begin{array}{l}\text { Mampu menemukan beragam permasalahan yang relevan dan unik dengan alasan yang } \\
\text { salah }\end{array}$ & 3 \\
\hline & $\begin{array}{l}\text { Mampu menemukan beragam permasalahan yang relevan dan unik dengan alasan yang } \\
\text { benar }\end{array}$ & 4 \\
\hline \multicolumn{3}{|c|}{ Kemampuan Berfikir Kreatif dalam Menemukan Solusi (Solution Finding) } \\
\hline \multirow{5}{*}{$\begin{array}{c}\text { Kefasihan } \\
\text { (fluency) }\end{array}$} & Tidak mampu menemukan solusi yang relevan dari fenomena yang diberikan & 0 \\
\hline & Mampu menemukan satu solusi yang relevan namun dengan a lasan yang salah & 1 \\
\hline & Mampu menemukan satu solusi yang relevan disertai alasan yang benar & 2 \\
\hline & Mampu menemukan bera gam solusi yang benarnamun dengan alasan yang salah & 3 \\
\hline & Mampu menemukan bera gam permasalahan yang benar disertaialas an yang benar & 4 \\
\hline \multirow{5}{*}{$\begin{array}{l}\text { Kelenturan } \\
\text { (flexibility) }\end{array}$} & Tidak mampu menemukan solusi yang relevan dari fenomena yang diberikan & 0 \\
\hline & Mampu menemukan satu solusi yang relevan namun dengan alasan yang salah & 1 \\
\hline & Mampu menemukan satu solusi yang relevan disertai a la san yang benar & 2 \\
\hline & $\begin{array}{l}\text { Mampu menemukan beragam solusi dari berbagai perspektif atau sudut pandang yang } \\
\text { berbeda namun dengan alasan yang salah }\end{array}$ & 3 \\
\hline & $\begin{array}{l}\text { Mampu menemukan beragam solusi dari berbagai perspektif atau sudut pandang yang } \\
\text { berbeda disertai alasan yangbenar }\end{array}$ & 4 \\
\hline \multirow{5}{*}{$\begin{array}{c}\text { Keaslian } \\
\text { (originality) }\end{array}$} & Tidak mampu menemukan solusi dari fenomena yang diberikan & 0 \\
\hline & Mampu menemukan satu solusi yang relevan dan unik namun dengan a la san yang salah & 1 \\
\hline & Mampu menemukan satu solusi yang relevan dan dengan alasan yang benar & 2 \\
\hline & Mampu menemukan beragam solusi yang relevan dan unik dengan a lasan yang sa lah & 3 \\
\hline & Mampu menemukan bera gam solusi yang relevan dan unik dengan a lasan yang benar & 4 \\
\hline
\end{tabular}


Instrumen tes yang sudah dikembangkan kemudian divalidasi. Tenaga ahli yang dilibatkan dalam validasi ini berjumlah 3 orang ( 2 orang bergelar doktor pendidikan fisika dan satu orang bergelar doktor fisika). Berdasarkan hasil validasi didapatkan bahwa semua soal dinyatakan valid dengan sedikit perbaiakan seperti perbaikan dari se gi tata tulis dan tata bahasa. Instrumen tes yang sudah divalidasi kemudian direvisi sesuai dengan saran validator. Berikut adalah hasil validasi isi oleh 3 orang ahli.

Tabel 2. Hasil validasi isi oleh ahli

\begin{tabular}{cccc}
\hline \multirow{2}{*}{ Nomor Soal } & \multicolumn{3}{c}{ Penilaian Ahli } \\
\cline { 2 - 4 } & 1 & 2 & 3 \\
\hline 1 & valid & valid & valid \\
2 & valid & valid & valid \\
3 & valid & valid & valid \\
4 & valid & valid & valid \\
5 & valid & valid & valid \\
\hline
\end{tabular}

Selain itu, dalam penelitian ini juga dikembangkan rubrik penilaian (pedoman pensekoran) kemampuan berfikir kreatif dalam pemecahan masalah. Pedoman pensekoran ini mengadaptasi pedoman pensekoran yang dikembangkan oleh Bosch yaitu sebagaiberikut [12-14].

\section{Tahap Penyebaran}

Instrumen tes yang sudah direvisi kemudian dilakukan uji coba terbatas di sekolah. Hasil uji coba kemudian dianalisis untuk mengetahui tingkat reliabilitas instrumen tes. Berdasarkan hasil uji reliabilitas dengan menggunakan persamaan korelasi product moment pearson diperoleh koefisien korelasi sebesar $0.79\left(\mathrm{r}_{\mathrm{xy}}=0.79\right)$. Besar koefisien korelasi ini kemudian dikonsultasikan dengan kriteria reliabelitas tes Arikunto [10].

Setelah hasil perhitungan dikonsultasikan dengan tabel kategori reliabilitas dapat disimpulkan bahwa instrumen tes kemampuan berfikir kreatif dalam pemecahan masalah memiliki reliablitas yang tinggi. Berdasarkan hasil validasi dan reliabilitas di atas dapat disimpulkan bahwa instrumen tes yang sudah dikembangkan layak untuk dipergunakan.

Tebel 4. Kategori reliabilitas instrumen tes

\begin{tabular}{cc}
\hline Batasan & Kategori \\
\hline $0.80<\mathrm{r}_{\mathrm{xy}} \leq 1.00$ & Sangat tinggi \\
$0.60<\mathrm{r}_{\mathrm{xy}} \leq 0.80$ & Tinggi \\
$0.40<\mathrm{r}_{\mathrm{xy}} \leq 0.60$ & Cukup \\
$0.20<\mathrm{r}_{\mathrm{xy}} \leq 0.40$ & Rendah \\
$\mathrm{r}_{\mathrm{xy}} \leq 0.20$ & Sangat rendah \\
\hline
\end{tabular}

Berikut adalah salah satu contoh soal yang ada dalam instrumen tes kemampuan berfikir dalam penelitian ini.

\section{Fenomena I:}

Bayangkan kamu adalah salah satu anggota dari tim mancing mania yang sedang pergi memancing menggunakan perahu ke tengah laut. Ketika tiba di tengah laut, hal yang tidak terduga terjadi. Perahu yang kalian gunakan terhempas gelombang ganas dan terdampar di sebuah pulau terpencil yang jauh dari pemukiman penduduk. Namun untungnya peralatan seperti Generator $600 \mathrm{~W} / 240 \mathrm{~V}$, kebel penghubung dan beberapa bola lampu 50W/120V masih aman dari terjangan badai. Sambil menunggu untuk diselamatkan, kalian memutuskan menggunakan Generator untuk mengoperasikan lampu-lampu tersebut sebagai penerang disaat malam tiba dan sekaligus untuk memberi signal keberadaan kalian kepada regu penyelamat. Namun ketika dicoba merangkai satu lampu dengan menggunakan generator, tiba-tiba bola lampu yang kalian gunakan rusak. Beruntung masih banyak bola lampu yang tersisa yang masih dapat digunakan. Kamupun diminta untuk menyelidiki sekaligus dipercaya untuk da pat memberi solusi atas permasalahan tersebut.

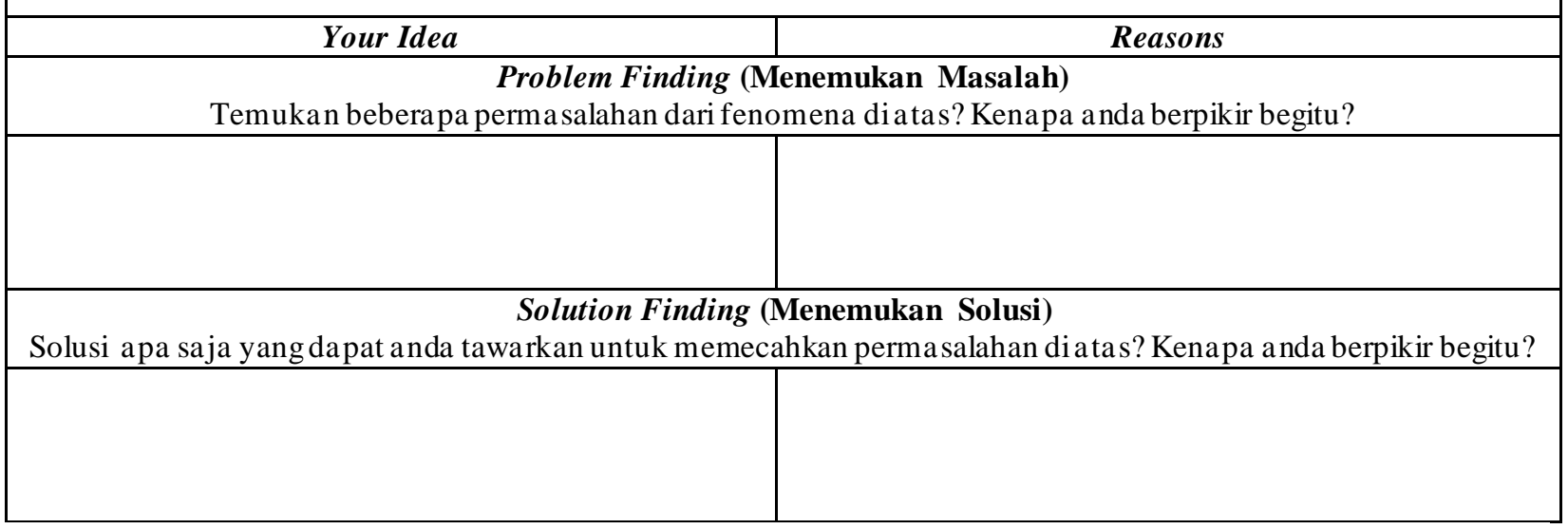


Desain instrumen soal di ata mengarahkan siswa dalam mengembangkan kemampuan berpikir kritis. Siswa pertama menemukan masalah pada fenomena yang diberikkan. Menganalisis fenomena dalam beberapa peta konsep yang yang dipetakan siswa membuat siswa lebih berpikir fokus pada fenomena permasalahan. Setelah menemukan masalah siswa diminnta menemukan solusi. Proses penemuan solusi menorong siswa untuk meningkatkan literasi sains, kerja keras, kolaborasi antar kelompok sehingga mampu menyelesaikan setiap permasalahan pada setiap fenomena yang diberikan [15-19].

Dengan demikian, instrumen tes yang dikembangkan dapat diterapkan dan mampu mengukur kemampuan berpikir kreatif siswa dalam menyelesaikan permasalahan pada fenomena yang diberikan dalam soal.

\section{KESIMPULAN}

Penelitian bertujuan mengembangkan instrumen tes model ideation-explanation untuk mengukur kemampuan berfikir kreatif dalam proses pemecahan masalah. Hasil penelitian memperlihatkan bahwa instrumen tes yang dikembangkan valid dan memiliki reliabilitas yang tinggi. Dengan demikian dapat disimpulkan bahwa instrumen tes ini layak untuk dipergunakan. Pada penelitian ini, materi yang digunkan terbatas pada materi arus listrik. Oleh karena itu, disarankan bagi peneliti selanjutnya untuk mengembangkan instrumen tes pada materi yang lain. Selain itu, peneliti menyarankan agar instrumen tes ini digunakan secara bersama-sama dengan instrumen tes yang lain terutama instrumen tes yang dikembangkan dengan mengadaptasi bentuk Torrance Tests of Creative Thinking (TTCT) dan bentuk tes lainnya .

\section{DAFTAR PUSTAKA}

[1] Kusuma, Y. (2010). Creative Problem Solving. Tanggerang: Rumah Pengetahuan.

[2] Al-khatib, B. A. (2012). The Effect of Using Brainstorming Strategy In Developing Creative Problem Solving Skills Among Female Students In Princess Alia University College. American International Journal of Contemporary Research, 2 (10), 29-38.

[3] Brookhart, S. M. (2010). How to Assess HigherOder Thingking Skill in Your Classroom. Alexandria: Virginia USA.

[4] Treffinger, D. J., Young, G.C., Selby, E.C., Shepardson, C. (2002). Assessing Creativity: A Guide for Educators. Florida: Center for Creative Learning Sara sota.

[5] Isaksen, S. G. (1995). on the conceptual foundations of creative problem solving. a response to magyary beck. Creative of Inovation Managemen, 4 (1), 1628-1635.

[6] Kementerian Pendidikan dan Kebudayaan (2014). Impelementasi Kurikulum 2013. Jakarta: Indonesia

[7] Redhana, I. W., Sya'ban, S. (2014). Pengembangan Tes Keterampilan Berpikir Kreatif . Seminar Nasional Riset Inovatif II, 18-25.

[8] Kim, K.H. (2006). Can we trust creativity tests? A review of the torrance tests of creative thinking (TTCT). Creativity Research Journal, 18 (1), 3 14.

[9] Hidayat, S.R., Setyadin, A.H., Hermawan, Kaniawati, I., Suhendi, E., Siahaan P., dan Samsudin, P. (2017) Pengembangan Instrumen Tes Keterampilan Pemecahan Masalah pada Materi Getaran, Gelombang, dan Bunyi. Jurnal Penelitian \& Pengembangan Pendidikan Fisika. 2 (2), 157-166.

[10] Arikunto, S. (2002). Prosedur Penelitian Suatu Pendekatan Praktik. Jakarta: Rineka Cipta.

[11]Wang, H.C, Chang, C.Y \& Li, T.Y (2005). Automated Scoring for Creative Problem Solving Ability With Model Ideation-Explanation Modeling. Proceedings of The 13th International Conference On Computers In Education (ICCE2005).

[12] Moma, L. (2015). Pengembangan Instrumen Kemampuan Berpikir Kreatif Matematis Untuk Siswa SMP. Jurnal Matematika dan Pendidikan Matematika 4 (1), 27-41.

[13] Isrok'atun, I., Hanifah, N., \& Sujana, A. (2018). Melatih Kemampuan Problem Posing melalui Situation-Based Learning bagi Siswa Sekolah Dasar. UPI Sumedang Press.

[14] Ishak, M., Jekti, D. S. D., \& Sridana, N. (2017). Pengaruh Penerapan Pendekatan Saintifik Menggunakan Model Pembelajaran Discovery Dan Kooperatif Tipe Stad Terhadap Kemampuan Berpikir Kreatif Peserta Didik SDN 13 Ampenan. Jurnal Pijar Mipa, 12(1).

[15] Kurniawati, D., Muhlis, M., \& Makhrus, M. (2020). Validitas Multimedia Interaktif pada Materi Kemagnetan Berbasis Indikator Penguasaan Konsep dan Kemampuan Berpikir Kreatif. Jurnal Pijar Mipa, 15(5), 527-532.

[16] Ibrahim, I., Gunawan, G., \& Kosim, K. (2020). Validitas Perangkat Pembelajaran Fisika Berbasis Model Discovery dengan Pendekatan Konflik Kognitif. Jurnal Pijar Mipa, 15(3), 214-218.

[17] Izzatunnisa, I., Andayani, Y., \& Hakim, A. (2019). Pengembangan LKPD berbasis pembelajaran penemuan untuk meningkatkan kemampuan literasi sains peserta didik pada materi kimia SMA. Jurnal Pijar Mipa, 14(2), 49-54. 
J. Pijar MIPA, Vol. 16 No.1, Januari 2021: 57-63

ISSN 1907-1744 (Cetak)

DOI: $10.29303 /$ jpm.v16i1.1700

ISSN 2460-1500 (Online)

[18] Wulandari, N. I., Wijayanti, A., \& Budhi, W. (2018). Efektivitas Model Pembelajaran Problem Based Learning Terhadap Hasil Belajar Ipa Ditinjau dari Kemampuan Berkomunikasi Siswa. Jurnal Pijar MIPA, 13(1), 51-55.

[19] Busyairi, A., \& Sinaga, P. (2015, October). Profil keterampilan pemecahan masalah secara kreatif siswa SMA pada pokok bahasan listrik dinamis. In PROSIDING SEMINAR NASIONAL FISIKA (E-JOURNAL) (Vol.4, pp.SNF2015-IV). 